\title{
Waardenburg Syndrome Type 1: A Case Report
}

\author{
Armyta Denissafitri ${ }^{\mathrm{a}}$, Aprilin Krista Devi ${ }^{\mathrm{a}}$, Sawitri ${ }^{*}$
}

armyta_fitri@yahoo.com

${ }^{a}$ Department of Dermatology and Venerology Faculty of Medicine Universitas Airlangga/Dr. Soetomo General Academic Teaching

Hospital, Surabaya, Indonesia

\begin{abstract}
As a result of the deficiency of melanocytes in the hair, skin, and eyes, Waardenburg syndrome is an extremely uncommon hereditary condition. Clinical aspects, such as major and minor criteria, are often used to make a diagnosis based on a patient's symptoms and signs. An infant with Waardenburg syndrome type 1 had a white forelock, sensorineural hearing loss, depigmented macules on the skin, and premature graying hair.
\end{abstract}

Keywords: Waardenburg syndrome; white forelock; hereditary condition

\section{Introduction}

Congenital pigment defects, particularly white patches accompanying sensorineural deafness, are the hallmarks of Waardenburg syndrome (WS). As many as 1 in 42, 000 persons suffer with WS at any one time (Hayashi et al.,2019; Bekkenk et al.,2020). As a result of the clinical and genetic anomalies, there are four distinct kinds of Waardenburg syndrome. These are WS1, WS2, WS3, and WS4 (Sadiq et al., 2019). Forelock whitened, sensorineural hearing loss, skin depigmentation, and premature graying of hair were all seen in this 7-month-old kid with WS1.

\section{Case presentation}

A 7-month-old boy was consulted from the Pediatric department that diagnosed with subdural hygroma, west syndrome and suspect Waardenburg syndrome to our Dermatology Venereology department of Dr. Soetomo General Hospital Surabaya with a chief complaint of white hair since birth. The white hair first appeared on the forehead and getting wider. His parents also complained of white patches on his back since birth. The patient also did not turn around when called or hear loud voices. There were no color changes in his eyes. There were no same complaints on his family. 
The patient was born in aterm age of the pregnancy. The birth body weight was 3300 grams and immunizations were complete for his age. His mother was 33 years old, this is the second pregnancy. His mother had tried to abort by taking traditional herbs in the first semester of pregnancy.

According to the results of a first physical examination, his weight was 7,000 grams and the pulse and respiration rates were both 132 times per minute. His body temperature was also measured at $36.5^{\circ} \mathrm{C}$. Dyspnea, cyanosis, or anemia were not detected during the patient's head and neck assessment. The evaluation of the lungs, heart, and thorax were all normal. They couldn't feel anything in the abdomen, spleen, or liver. The upper and lower limbs were free of edema and were warm to the touch when palpated.

Dermatological examination showed white forelock and normal hair on scalp region and multiple depigmentation macules in varians size 1 to 2 centimeter on his posterior thoracalis region (Figure 1).

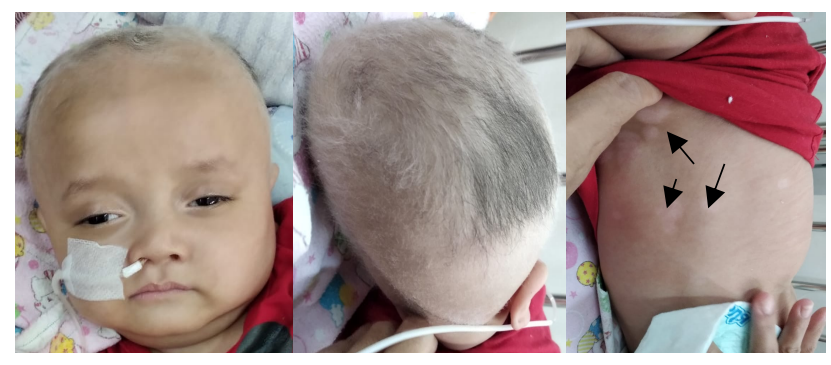

Fig. 1. White forelock and depigmentation macules

The Histopathology examination from depigmented macule revealed basal cell hypopigmentation and the number of melanocytes decreased at epidermis with Hematoxylin-Eosin (HE) staining (Figure 2). The conclusion was basal cell hypopigmentation accordance with piebaldism.

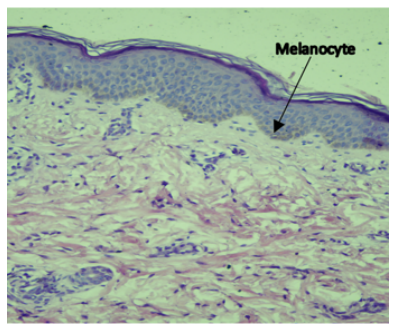

Fig. 2. Histopathology feature from depigmented macules of the patient.

No abnormalities of the iris (heterochromia irides) or lateral displacement of inner canthi of the eyes (dystopia canthorum) were found after a consultation with the ophthalmologic department. The result of ENT department consultation from his otoacoustic emission was abnormal and ENT department was planned to do 
auto acoustic brainstem response (AABR) but this examination was not done because the patient already passed away.

Sunscreen is the only treatment for this situation. Individuals with Waardenburg syndrome have a higher risk of sunburn, hence UV protection is recommended. Hypopigmentation may increase the risk of skin cancer in the future, however no specific instances of skin cancer connected with hypopigmentation have been reported (Bekkenk et al., 2019).

The patient was diagnosed with Waardenburg syndrome type 1 based on the presence of white forelock, sensorineural hearing loss, depigmentation macule, and premature graying hair.

\section{Discussion}

Waardenburg syndrome, first reported by Petrus Johannes Waardenburg in 1952, is a rare genetic disorder and mostly have autosomal dominant inheritance (Hayashi et al., 2019; Haj Kassem et al., 2018). Piebaldism is an indistinguishable hallmark of WS from the cutaneous symptoms, however other traits may be present depending on the mutation type (Bekkenk et al., 2020). Spots and freckles are less prevalent than white patches. WS type 1 is passed down in an autosomal dominant manner, with mutations in the PAX3 gene on chromosome 2's long arm being the most common cause (Dayasiri et al.,2019). Sensorineural hearing loss and heterochromia irides are the most common causes of hearing loss in children. In order to be diagnosed with WS 1, two main requirements must be met or one major and two minor criteria must be met (Table 1) (Hayashi et al., 2019).

\begin{tabular}{ll}
\hline \multicolumn{2}{l}{ Table 1 Diagnostic Criteria of Waardenburg Syndrome } \\
\hline Major criteria & Minor criteria \\
\hline Characteristic white forelock & Depigmented macules or patches \\
\hline Pigmentary anomalies of the iris & Synophrys \\
\hline Congenital sensorineural deafness & Broad nasal root \\
\hline Dystopia canthorum & Nose hypoplasia \\
\hline An affected first-degree relative & Early graying the hair by age 35 years
\end{tabular}

Two main criteria, including the white forelock and congenital sensorineural deafness, were used to identify the present case as WS1. Two minor criteria, depigmented macules and early graying hair, were also considered. Dystopia canthorum is missing in WS2, but it is present in WS3, with the exception of the existence of upper limb deformities, which is the sole difference between the two. Due to its long association with Hirschsprung illness, the Waardenburg-Shah Syndrome (WS4) may be easily diagnosed (Sadiq et al., 2019). 
Congenital deafness is caused by WS, an auditory-pigmentary condition that affects $2 \%-3 \%$ of the population. As many as 2 to 3 instances per 100,000 people globally are thought to be affected by the disease (Saleem, 2019). In this case, the patient did not turn his head around when called or hear loud voices. The result from his otoacoustic emission was abnormal and ENT department was planned to do auto acoustic brainstem response (AABR) but this examination was not done because the patient already passed away.

There is presently no cure for WS, which is a hereditary condition. Management of WS is interdisciplinary and includes patient education and early intervention in chosen individuals. All WS patients and their families should seek out genetic counseling and testing (Saleem, 2019). People with WS are more likely to become sunburned, thus they need to use sunscreen (Hayashi et al., 2019; Haj Kassem et al., 2018).

\section{Conclusion}

Our community is quite small, thus it's crucial to describe this instance of Waardenburg syndrome type 1 . This hereditary condition necessitates parental education.

\section{Acknowledgements}

I'd want to express my thanks to the Dermatology and Venereology faculty at the Airlangga University Faculty of Medicine, as well as to my loved ones and friends for their unwavering encouragement and well wishes.

\section{References}

Bekkenk M.W., Wolkerstorfer A. 2020. Disorders of Hypopigmentation. In: Hoeger P, Kinsler V, Yan A, editors. Harper's Textbook of Pediatric Dermatology. Oxford: Wiley Blackwell. p. 1492-8.

Dayasiri K.C., Perera C., Bandara W., Ranasinghe J. 2019. Waardenburg syndrome type 1 in an infant diagnosed with congenital hypothyroidism. J Nepal Paediatr Soc. 39(1): 60-2.

Haj Kassem L., Ahmado M.F., Sheikh Alganameh M. 2018. A rare case of seven siblings with Waardenburg syndrome: A case report. J Med Case Rep. 12(1): 1-5.

Hayashi M., Suzuki T. Albinism and Other Genetic Disorders of Pigmentation. 2019. In: Kang S, Amagai M, Bruckner AL, Margolis DJ, McMichael AJ, editors. Fitzpatrick's Dermatology $9^{\text {th }}$ ed.. New York: McGraw-Hill Education. p.1309-29.

Sadiq S., Langah A., Siyal A.A., Ain Ali N.U. 2019. Waardenburg Syndrome: A Case Report. Asian J Pediatr Res. 2(4): 1-4.

Saleem M.D. 2019. Biology of human melanocyte development, Piebaldism, and Waardenburg syndrome. Pediatr Dermatol. 36(1): 72-84. 